Virtual Mentor. August 2003, Volume 5, Number 8.

doi: 10.1001/virtualmentor.2003.5.8.hlaw1-0308

Health Law

\title{
Overriding Parental Decision to Withhold Treatment
}

\section{Physicians are obligated in many jurisdictions to perform life-sustaining treatments on premature infants with serious developmental or physical impairments, even if it goes against the parents' wishes.}

\author{
Michael Woods, MPH
}

Jennifer Moore was admitted to the hospital with symptoms of premature labor. An ultrasound revealed that her fetus weighed approximately $629 \mathrm{~g}$ and had an estimated gestational age of 24 weeks, a full 14 weeks before term. Doctors also feared that Mrs. Moore might have a life-endangering infection. Dr. Black, Jennifer's attending obstetrician, and Dr. Hudson, a neonatologist, informed Mrs. Moore and her husband that if the baby were born alive and survived, she would suffer severe impairments. The Moores were also told that the hospital had never been able to save a child born this prematurely and that, although every year for the past 5 years, the birth-weights of children who survived had gotten lower, anything they did to sustain life would be guesswork. Dr. Black indicated that, due to Mrs. Moore's lifethreatening infection, an abortion was not an option. Finally, the physicians informed the Moores that the baby would be born within 24 hours.

Considering all their options, the Moores orally requested that if the baby were born alive, no heroic measures be used to keep her alive. Dr. Hudson recorded the Moores' oral request in the medical records, and Dr. Black informed the nursing staff that no neonatologist would be needed at delivery.

After further consultation, however, Dr. Black concluded that if the Moores' baby were born alive and weighed more than 500 g, the medical staff would be obligated by hospital policy to administer life-sustaining procedures even if the Moores did not consent to it. Dr. Black explained this to Mr. Moore who forcefully reiterated the couple's desire that their baby not be resuscitated. Consultation on the option of seeking court authority to treat was brought up but, with the estimated time of delivery unknown, no action was taken.

Approximately 11 hours later Heidi Moore was born. The attending neonatologist, Dr. Fields, determined that Heidi was viable and instituted resuscitative measures. Although Heidi survived, she suffered, as had been anticipated, from devastating neurological impairment.

\section{Legal Analysis}

The above facts are adapted from HCA, Inc v Miller [1]. The Millers filed a lawsuit against HCA, Inc, HCA-Hospital Corporation of America, Hospital Corporation of America, and Columbia/HCA Health Care Corporation (collectively "HCA"), asserting that they were liable for the actions of their subsidiary hospital. Based on a negligence theory, the Millers asserted that HCA was liable for treating their daughter, Sydney Miller, without their consent, and second, for having a policy that mandated the resuscitation of newborn infants weighing more than $500 \mathrm{~g}$. The Millers also asserted that HCA was directly liable for not preventing such treatment without consent. Based on the jury's findings, the trial court entered judgment in favor of the Millers in the amount of \$29.4 million in past and future medical expenses, \$13.5 million in punitive damages, and \$17.5 million in prejudgment interest. HCA appealed.

The central question before the Court of Appeals of Texas, Fourteenth District, was whether parents have a legal right 
to deny their child urgently needed life-sustaining medical treatment. If they did, what were the obligations of the doctors and hospital personnel? Should the doctors have sided with the Millers, the hospital, or should they have sought court intervention? "The question whether, and under what circumstances, a state may order medical treatment for a child over parental objections places 3 sets of interests in contention: (1) the "natural rights" of parents; (2) the responsibilities of the state; and (3) the personal needs, ie, the best interests, of the child" [2].

On the one hand, the court explained, parents have a legal duty to provide needed medical care to their children and, in Texas, the failure to provide such care is a criminal offense. "On the other hand, it is well-settled that parents enjoy a substantive constitutional right to make decisions concerning their children's care and welfare according to the dictates of their own consciences" [3]. The court noted that Texas law gives parents the right of informed consent regarding their children's medical care. "The logical corollary to the doctrine of informed consent is the right to informed refusal" [4]. Texas law at the time of Sydney's birth also allowed parents to withhold or withdraw life-sustaining medical treatment from a child with a certifiably terminal condition.

On this issue the court reasoned that the Texas legislature had expressly given parents a right to withhold or withdraw life-sustaining medical treatment, urgently needed or not, for a child with a certifiably terminal condition, but it did not extend that right to the parents of children with nonterminal impairments, deformities, or disabilities. Thus, the court concluded that the Millers had a right to withhold life-sustaining treatment for Sydney only to the extent that her condition was certifiably terminal and unless it was certified terminal that right could not be exercised. The court concluded that there was no evidence that Sydney's condition before or after birth was (or could have been) certified as terminal, and following her birth, Sidney's condition proved, with the efforts of her doctors, not to be terminal.

The third competing interest is that of the state. The court explained that the state, under the rubric of parens patriae (the parents' role), can act to guard the well-being of minors, even if doing so limits the freedom and authority of their parents. "Although parents enjoy the right to make decisions concerning their children's care, their decisions must yield to state intervention if they fail in their legal duty to provide reasonably necessary medical care for their children" [5]. The court explained that in Texas, the rights of a parent are subject to court orders, including an order granting a governmental entity authority to consent to a child's medical treatment initially refused by the parents. Notably, in Texas, the court pointed out that it is not the physician who has the right or obligation to seek court intervention, but the appropriate governmental agency, which the physician must notify. Therefore, the court concluded, a health care provider's obligation is generally to comply with a patient's (or parent's) refusal of medical treatment until ordered by the court to do otherwise.

The court explained that in a situation where the medical treatment proposed for a child is not life-saving or lifesustaining, a court order is needed to override a parent's refusal to consent to the treatment. By contrast, the court explained, where the need for life-sustaining medical treatment is an emergency, time constraints will often not permit resort to the courts. "A medical practitioner will generally not be liable for treating a minor patient without parental consent when an emergency makes it impractical or dangerous to delay treatment in order to obtain such consent" [6]. "The 'emergency exception' reflects the view that it is cruel to allow a child to suffer pain for an extended period of time because a health care professional refuses to treat for fear of being sued by the patient's parents" [7]. Thus, the court concluded that (1) where the need for life-sustaining medical treatment is or becomes an emergency while a nonterminally ill child is under a physician's care, and (2) where the child's parents refuse to consent to that treatment (ie, the situation Sydney Miller was in), a court order is not necessary to override parental refusal. That is, because of the existence of an emergency, treatment is legally permissible, and the court does not need to adjudicate the best interest of the child in approving the physician's decision to override a parental refusal for treatment.

In sum, the court held that because there was no evidence that Sydney's condition was certified as terminal, before or after birth (or could have been certified as terminal), the Millers had no right to deny her urgently needed lifesustaining medical treatment. If Sydney's condition had been certified as terminal, the Millers would have been legally allowed to withhold nonemergency, life-sustaining treatment under Texas law. The court also held that no court order was needed to override the Millers refusal of treatment because of the judge's characterization of Sydney's birth as an emergency necessitating swift action. In reversing the trial court's decision, the Court of Appeals rendered judgment that the Millers take nothing on their claims against HCA. The case, now on appeal, was argued before the Texas Supreme Court in April 2002, and has not been decided. 
The dissenting opinion argued that the Texas law outlining when parents can withhold or withdraw life-sustaining medical treatment from a child with a certifiably terminal condition did not supercede their right to refuse. The dissenting judge explained that the act expressly allowed, and did not deny, the Millers the right to withhold or withdraw life-sustaining procedures in a lawful manner. That is, although Sydney's condition was not terminal and therefore not considered within the act, the Millers still retained their right to refuse. More importantly, the dissenting opinion disagreed with the majority opinion's conclusion that, given the circumstances of Sydney's birth, a court order was not necessary to override the parents' refusal. Specifically, the dissent disagreed with the majority's contention that there was "no legal or factual issue for the court to decide regarding the provision of such treatment" [1] arguing that the most important issue, the best interest of the child, could have been determined to eliminate any conflict of interest. The dissenting opinion characterized the Millers' circumstances as analogous to a situation where nonemergency or nonlife-sustaining medical treatment is proposed and parents refuse. The dissenting judge disagreed that the time constraints did not permit resort to the courts, pointing out that 11 hours elapsed after the Millers informed their doctors that they would continue to standby their original decision to not seek resuscitative measures if the baby were born alive. The only emergency, the dissent admonished, if any, was due to the doctors and medical personnel's indecision and delay. The dissent argued that the majority opinion asserted that this was an emergency without a jury finding. The dissenting opinion suggested that the doctors and medical personnel decided to resuscitate Sydney, knowing the Millers were there and could be consulted for their consent; and that the situation was not a medical emergency, allowing the physicians to proceed with treatment without the Millers' consent.

\section{Questions for Discussion}

1. Given the judges' interpretation of Texas law, parents can only refuse life-saving treatment if their child's medical condition is certifiably terminal, (which Sydney was not), the physician did not have to notify the appropriate government because the situation was, in the judge's view, an emergency. Given the above legal analysis, what would be the most ethical course of action for the physician involved? Respect the Millers' request? Comply with the hospital's policy? Or seek a decision in the courts?

2. Do you think that HCA owes the Millers anything for creating and sustaining an absolute policy that enabled the hospital to contravene parental wishes for seriously ill newborns? If yes, do you think the proposed $\$ 250,000$ cap on noneconomic damages is adequate?

3. In your opinion, did the HCA policy create more or less harm than respecting the Miller's request would have created?

4. Are the restrictions on the parents' right to refuse treatment sufficient to prevent infanticide of unwanted children? Should the law be changed to be more restrictive? Less restrictive (ie, fetuses or babies need not be terminally ill for parents to exercise their right to refuse)?

\section{References}

1. HCA Inc v Miller, 36 SW3d 187 (Tex App 2000).

2. Penkower JA. The potential right of chronically ill adolescents to refuse life-saving medical treatment-fatal misuse of the mature minor doctrine. DePaul L Rev. 1996;45:1165-1174.

\section{Google Scholar}

3. Ibid, 1173-1174.

4. Ibid, 1170.

5. See Penkower, 1174.

6. Veilleux DR. Medical practitioner's liability for treatment given child without parent's consent. ALR. 2001;67(4);511-518.

Google Scholar

7. See Penkower, 1177.

The viewpoints expressed on this site are those of the authors and do not necessarily reflect the views and policies of 
the AMA.

(C) 2003 American Medical Association. All Rights Reserved. 